\title{
A Review of the Differential Diagnosis of Acute Infectious Conjunctivitis: Implications for Treatment and Management
}

This article was published in the following Dove Press journal:

Clinical Ophthalmology

\author{
Elizabeth Yeu' \\ Scott Hauswirth ${ }^{2}$ \\ 'Virginia Eye Consultants, Norfolk, VA, \\ USA; ${ }^{2}$ Department of Ophthalmology, \\ Sue Anschutz-Rodgers Eye Center, \\ University of Colorado School of \\ Medicine, Aurora, CO, USA
}

\begin{abstract}
The diagnosis of acute infectious conjunctivitis can be difficult. Clinical ambiguity exists between the acute viral and bacterial as well as the allergic forms, which can confound diagnosis. Also, discrimination between viral or bacterial origins of infectious conjunctivitis based on historical, nonspecific, clinical signs and symptoms contributes to a high rate of misdiagnosis and overuse of antibiotic treatment. Therefore, in order to effectively treat acute infectious conjunctivitis, physicians must be aware of the clinical signs and symptoms and available diagnostic tests that can provide a more accurate differential diagnosis.
\end{abstract}

Keywords: allergic conjunctivitis, bacterial conjunctivitis, conjunctivitis, viral conjunctivitis

\section{Introduction}

Conjunctivitis is a collective term for a diverse group of diseases that are characterized by inflammation of the conjunctiva. ${ }^{1}$ The most common cause of infectious conjunctivitis is viral infection ( $\sim 80 \%$ of cases), followed by bacterial. ${ }^{1,2}$ The noninfectious forms are allergic, mechanical/irritative/toxic, immune-mediated, and neoplastic. ${ }^{1}$ Of noninfectious conjunctivitis, the allergic form is the most common, affecting approximately $40 \%$ of the US population. ${ }^{2}$ Conjunctivitis can also be classified as acute, chronic, or recurrent, ${ }^{1,2}$ according to the mode of onset and severity of the clinical response. ${ }^{2}$ Most cases of viral and bacterial conjunctivitis are considered acute and, less frequently, as hyperacute. The mechanical/irritative/toxic, immune-mediated, and neoplastic forms are typically associated with chronic inflammation, ${ }^{1}$ and the toxic form can have an acute onset. Allergic conjunctivitis can be chronic, with possible onset in childhood, and present with acute exacerbations related to seasonal factors or contact lens use, for example. ${ }^{1}$

Conjunctivitis is a highly common presentation in the primary care setting. It is responsible for $\sim 2 \%$ of all medical consultations in the United States ${ }^{3}$ and countless self-referrals to community pharmacies. ${ }^{4}$ It is difficult to accurately capture the true epidemiology of conjunctivitis because of the high numbers of patients who may self-medicate or delay or decline to seek medical care, and because of inaccurate diagnosis in the primary medical care setting. Approximately $70 \%$ of all patients with acute red eye present to primary care and urgent care, ${ }^{5}$ posing a large economic and social burden. ${ }^{6-8}$ The pharmacoeconomic impact of infectious conjunctivitis is noteworthy and includes the cost of repeat diagnoses, referrals, insurance copays, patient medications, and lost productivity associated with
Correspondence: Elizabeth Yeu Virginia Eye Consultants, 24I Corporate Blvd, Norfolk, VA 23502, USA

Tel + I 757-622-2200

Email eyeu@vec2020.com 
absence from work or school. In the United States, acute conjunctivitis affects an estimated 6 million people per year, ${ }^{2}$ and bacterial conjunctivitis treatment alone costs the United States \$377-857 million annually. To the best of our knowledge, no health-related quality-oflife studies of patients with acute infectious conjunctivitis have been published.

The purpose of this narrative review is to provide practical guidance on the differentiation of acute infectious conjunctivitis in the primary care setting and to highlight disconnects between diagnosis and treatment.

\section{Challenges of Acute Infectious}

\section{Conjunctivitis Management and Diagnosis}

Eye care professionals tend to evaluate acute infectious conjunctivitis cases at secondary care visits. Patients with infectious conjunctivitis are suboptimally managed in primary care due to an underappreciation of the prevalence of viral conjunctivitis, as well as frequent antibiotic prescriptions ( $\sim 80 \%)$ for infectious conjunctivitis, ${ }^{9}$ despite guidelines that discourage antibiotic use for minor self-limiting illnesses..$^{10}$ Antibiotic prescription is a measure of presumed diagnosis of bacterial conjunctivitis, but the rate of clinical accuracy in diagnosing viral conjunctivitis may be $<50 \%$. ${ }^{9}, 11$ Observational evidence indicates that laboratory confirmation isolates bacterial pathogens in just $30-50 \%$ of suspected cases. $^{9,11}$

Misdiagnoses expose patients to unnecessary and ineffective antibiotic treatment. In the Antibiotic Resistance Monitoring in Ocular Microorganisms (ARMOR) surveillance study of 3237 ocular isolates collected from patients with bacterial eye infections (from 72 US centers from 2009 to 2013), nearly one-half had methicillin-resistant staphylococci. ${ }^{12}$ Although the contribution of topical antibiotics to antibiotic resistance is not easily confirmed, ${ }^{11}$ current resistance trends should be considered before treating common eye infections with antibiotics. ${ }^{13}$ Furthermore, prescribing antibiotics in cases of unconfirmed bacterial infection is not compliant with Antibiotic Stewardship initiatives, which are part of primary care and pediatric practice protocols. ${ }^{14} \mathrm{In}$ addition to the risk of antibiotic resistance, misdiagnosis can result in recurrent cases of infectious conjunctivitis, particularly among pediatric patients, or in cases that progress to serious ocular and extra-ocular complications.

There are several challenges to accurately diagnosing acute infectious conjunctivitis. First, clinical ambiguity exists between the acute viral and bacterial as well as the allergic forms, which can confound diagnosis. ${ }^{11}$ Discrimination between viral or bacterial origins of infectious conjunctivitis based on historical, nonspecific, clinical signs and symptoms, such as type of discharge, is difficult and not supported by evidence-based diagnostic criteria. ${ }^{11,15}$ Routine bacteriologic examinations are neither typically performed nor practical in the management of clinically suspected acute bacterial conjunctivitis, ${ }^{15}$ except in neonates. ${ }^{1}$ Culturing should also be considered for immunocompromised patients or for patients with hyperacute cases of infectious conjunctivitis. The misdiagnosis of infectious conjunctivitis is compounded by the view that all cases should be treated with topical ophthalmic antibiotics, even though most are selflimiting. ${ }^{16,17}$ Social factors, such as school policies or pressure to reduce absence from work, may also influence general practitioners to prescribe topical antibiotics. ${ }^{11}$ Lastly, the level at which patients enter the health care system can impact the accuracy of the diagnosis.

Guidelines and criteria for diagnosing and treating acute infectious conjunctivitis based on natural history and etiology are available. ${ }^{1}$ However, greater awareness of and adherence to differential diagnosis should be kept in mind to improve outcomes in patients presenting with suspected acute infectious conjunctivitis. ${ }^{17}$

\section{Epidemiology and Clinical Presentation}

Discriminating features of viral, bacterial, and allergic acute conjunctivitis are summarized in Table $1 . .^{1,2,18}$

\section{Viral Conjunctivitis}

Adenoviruses are the cause of most (65-90\%) cases of viral conjunctivitis, while the herpes simplex virus (HSV) is the cause of $1.3-4.8 \%$ of all cases of acute conjunctivitis. $^{2}$ Other viruses that are associated with conjunctivitis include varicella (herpes) zoster virus (VZV) and Molluscum contagiosum. ${ }^{1}$

Adenoviruses are nonenveloped viruses that are relatively resistant to disinfection. ${ }^{19}$ Adenoviral conjunctivitis is highly contagious, due in part to the capacity of the virus to survive in a desiccated state at room temperature for several weeks. ${ }^{20}$ Transmission risk is $10-50 \%$, and the infection may spread via personal contact or indirectly through shared items. ${ }^{2}$ Adenoviral conjunctivitis is selflimiting, with improvement of signs and symptoms within 5-14 days. ${ }^{1}$ Often, the condition presents as unilateral in early phases and eventually spreads to both eyes.

Adenovirus serotypes are associated with different types of ocular infection, ${ }^{21}$ including pharyngoconjunctival fever 
Table I Discriminating Clinical Features of Suspected Acute Conjunctivitis

\begin{tabular}{|l|l|l|l|l|l|}
\hline Type & Conjunctival & Itching & Discharge & Lymphadenopathy & $\begin{array}{l}\text { Associated Fever and } \\
\text { Sore Throat }\end{array}$ \\
\hline $\begin{array}{c}\text { Viral } \\
\text { Adenoviral } \\
\text { HSV } \\
\text { VZV }\end{array}$ & Follicular & Minimal & Watery & Common ( 50\%) & Common \\
\hline $\begin{array}{l}\text { Bacterial } \\
\text { Nongonococcal } \\
\text { Gonococcal }\end{array}$ & Papillary & Minimal & $\begin{array}{l}\text { Purulent } \\
\text { Mucopurulent } \\
\text { Hyperpurulent }\end{array}$ & Uncommon & Occasionally \\
\hline Chlamydial & Follicular & Minimal & Mucopurulent & Common & No \\
\hline $\begin{array}{l}\text { Allergic } \\
\text { Papillary with } \\
\text { chemosis }\end{array}$ & Severe & $\begin{array}{l}\text { Watery } \\
\text { Mucoid }\end{array}$ & None & No \\
\hline
\end{tabular}

Note: Data from these studies. ${ }^{1,2,18}$

Abbreviations: HSV, herpes simplex virus; VZV, varicella (herpes) zoster virus.

and epidemic keratoconjunctivitis (EKC; patient photos shown in Figure 1). Pharyngoconjunctivitis typically manifests bilaterally with fever and enlargement of the periauricular lymph nodes. ${ }^{2}$ EKC is more severe because of the adverse effect it can have on visual acuity; it is characterized by watery discharge, swelling, and redness, and involvement of lymph nodes on both sides of the neck. ${ }^{2,21}$ EKC is highly contagious, and asymptomatic patients who have contracted the disease may unknowingly spread the virus. ${ }^{21}$

A complication of EKC is the formation of pseudomembranes on the palpebral conjunctiva in the early and later stages of the condition. ${ }^{21,22}$ Manual removal of these membranes causes minor bleeding but no damage to the underlying epithelium, and may prevent symblepharon formation in cases with severe inflammation. ${ }^{22}$ Multifocal subepithelial infiltrates may develop in the cornea within $7-10$ days after the onset of clinical signs of infection. ${ }^{23}$ These can persist for weeks or even years in some cases. ${ }^{22}$ If left untreated, subepithelial infiltrates can cause scarring in the cornea, leading to irregular astigmatism and loss of visual acuity. ${ }^{24}$ Topical corticosteroids or steroid-sparing agents such as cyclosporine eye drops can be used to reduce the risk of scarring; ${ }^{22}$ however, topical corticosteroids should be used with caution, especially in later stages of
A

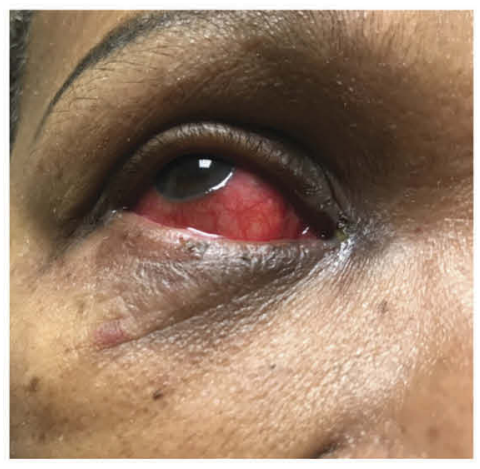

B

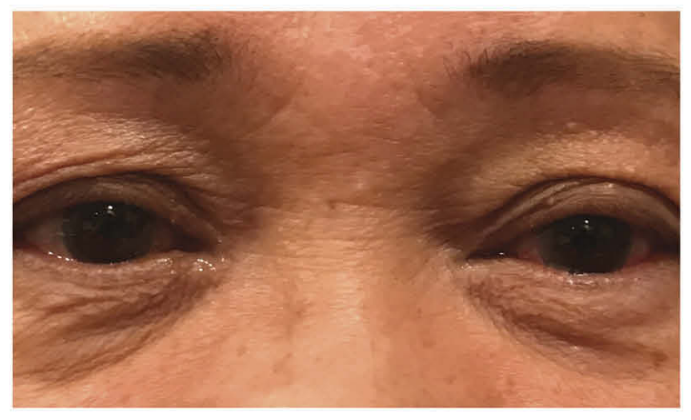

C

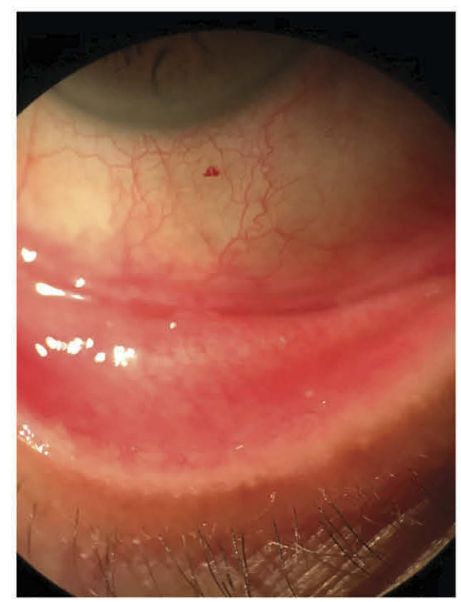

Figure I Case photographs of adenoviral conjunctivitis. (A) gross examination of acute adenoviral conjunctivitis; (B) bilateral AdenoPlus-positive EKC; (C) high magnification of the conjunctiva of positive EKC. Photos provided by Scott Hauswirth and Elizabeth Yeu. The patients have given permission for publication of these photos. Abbreviation: EKC, epidemic keratoconjunctivitis. 
recovery from adenoviral infection. ${ }^{21,25}$ It should be noted that subepithelial infiltrates may also be a feature of chlamydial conjunctivitis. ${ }^{1}$ As no medications are currently approved for adenoviral conjunctivitis, treatment is mainly supportive (cold compresses, chilled artificial tears) ${ }^{1}$ with instruction on infection control, as viral shedding continues after onset. ${ }^{1,25}$

There are few virucidal agents in preclinical development. Povidone-iodine (PVP-I) was under investigation as a potential treatment because of its broad-spectrum antimicrobial activity. ${ }^{1}$ An ophthalmic suspension composed of PVP-I $0.6 \%$ and the corticosteroid dexamethasone $0.1 \%$ (PVP-I 0.6\%/DEX 0.1\%) has been evaluated in a Phase 2 trial. ${ }^{26}$ Results from this study showed that PVP-I 0.6\%/DEX $0.1 \%$ treatment of patients with acute adenoviral conjunctivitis significantly improved clinical resolution and eradication of adenovirus in the study eye. ${ }^{26}$ Another compound, $\mathrm{N}$-chlorotaurine, has broad-spectrum microbicidal activity due to its nonspecific reaction mechanism, and was investigated for the treatment of viral conjunctivitis. ${ }^{27} \mathrm{~A} 1 \%$ solution of $\mathrm{N}$-chlorotaurine was well tolerated in patients with EKC and shortened the course of disease compared with gentamicin eye drops in a randomized phase $2 \mathrm{~b}$ study. ${ }^{27}$ Topical ganciclovir $0.15 \%$ ophthalmic gel is approved in the United States for acute herpetic keratitis only. ${ }^{1}$

Prior HSV infection is a predisposing factor for HSV conjunctivitis, and reactivation may be triggered by stress, trauma, ultraviolet light exposure, or other viral illnesses. ${ }^{1}$ HSV conjunctivitis is usually unilateral and characterized by bulbar conjunctival injection, thin and watery discharge, and mild follicular reaction of conjunctiva. ${ }^{1,2}$ Distinctive signs are vesicular eyelid lesions and pleomorphic or dendritic epithelial keratitis on the cornea or conjunctiva. ${ }^{1}$ As these signs on the cornea or conjunctiva are often present in the absence of eyelid or dermal lesions, they are best seen by instillation of vital dyes such as sodium fluorescein, lissamine green, or rose Bengal to assess the ocular surface. HSV conjunctivitis usually subsides within 4-7 days unless complications occur. Topical and/or oral antivirals are recommended to shorten the duration of illness. ${ }^{1,2}$ Because topical corticosteroids can potentiate HSV, ${ }^{1,2}$ they should be avoided, ${ }^{1}$ particularly in the presence of corneal or conjunctival epithelial disease. ${ }^{1,2}$ HSV can also cause EKC, which is difficult to distinguish clinically from adenoviral conjunctivitis. ${ }^{28}$

Active chicken pox and prior exposure to chicken pox or shingles are predisposing factors for VZV conjunctivitis. ${ }^{1}$ This condition is commonly unilateral in presentation.
Distinctive signs of VZV conjunctivitis include inflammation of the eyelids, conjunctiva, cornea, or uvea. ${ }^{2}$ Uveitis may present with increased intraocular pressure, which in some cases may rise to dangerous levels. ${ }^{29} \mathrm{VZV}$ conjunctivitis usually abates in a few days. ${ }^{1}$ A combination of oral antivirals and topical corticosteroids can be used with caution to manage VZV conjunctivitis, ${ }^{1,30}$ as topical antivirals alone are not effective in treating VZV conjunctivitis. ${ }^{1}$

\section{Bacterial Conjunctivitis}

Approximately $32 \%$ of acute infectious conjunctivitis cases are caused by bacteria, according to an evaluation of the prevalence of positive bacterial culture in adult patients who presented to their general practitioner with a red eye and either (muco)purulent discharge or glued eyelids. ${ }^{9}$ Bacterial conjunctivitis is typically unilateral but can sometimes affect both eyes. ${ }^{1}$ The staphylococcal species are the most common pathogens for bacterial conjunctivitis in adults, followed by Streptococcus pneumoniae and Haemophilus influenzae. ${ }^{2}$ In children, the bacterial disease is responsible for $50-75 \%$ of conjunctivitis cases, often caused by S. pneumoniae, H. influenzae, or Moraxella catarrhalis. The hyperacute form of bacterial conjunctivitis is caused by either Neisseria gonorrhoeae or Chlamydia trachomatis.

Acute bacterial conjunctivitis is characterized by a rapid onset of conjunctival redness and mucopurulent discharge. ${ }^{1,2}$ Symptoms may also include burning and itching, though these are less common. ${ }^{31}$ Acute bacterial conjunctivitis is selflimiting, resolving within 7-10 days. ${ }^{2}$ Use of broad-spectrum topical antibiotics should be delayed, ${ }^{1,2,10}$ and no evidence demonstrates the superiority of any topical antibiotic agent. ${ }^{1}$ Methicillin-resistant Staphylococcus aureus (MRSA) conjunctivitis is the cause of an estimated 3-64\% of ocular staphylococcal infections ${ }^{2}$ and requires management by an ophthalmologist with antibiotics that are active against MRSA, such as besifloxacin ophthalmic suspension. ${ }^{32}$

The rapid onset and progression of hyperacute bacterial conjunctivitis (often caused by $N$. gonorrhoeae) warrants immediate ophthalmic management to prevent corneal involvement and potentially perforation. ${ }^{1}$ Symptoms include purulent discharge, diminished visual acuity, eye tenderness, and swollen lymph nodes. The increasing incidence of gonorrhea infection was recognized in 2015 as an urgent public health threat in the United States. ${ }^{33}$ From 2013 to 2017 the rate of reported gonorrhea cases increased by $67 \%$ $\left(555,608\right.$ cases in 2017), ${ }^{34,35}$ with an $18.6 \%$ increase between 2016 and 2017. ${ }^{34}$ Gonococcal ocular infection can present in neonates after vaginal delivery by infected mothers. ${ }^{1}$ 
Treatment includes intramuscular ceftriaxone for adults, children, and neonates, and oral azithromycin or doxycycline for adults. $^{2}$ The Centers for Disease Control and Prevention treatment guidelines changed in 2015 to support the use of dual therapy with ceftriaxone and azithromycin due to the increased resistance of $N$. gonorrhoeae to the antimicrobials previously used for treatment. ${ }^{36}$ Bacterial conjunctivitis lasting more than 4 weeks is considered chronic. ${ }^{2}$

Chlamydia is the cause of $1.8-5.6 \%$ of all acute conjunctivitis cases. ${ }^{2}$ Chlamydial conjunctivitis primarily has a unilateral presentation with concurrent genital infection ${ }^{1}$ and presents with conjunctival redness, lymphoid follicle formation, or mild purulent discharge. ${ }^{1,2}$ A distinctive sign of this infection in adults is bulbar conjunctival follicles, which are absent in neonates/infants. ${ }^{1}$ Chlamydial conjunctivitis is typically spread through sexual contact. ${ }^{1}$ Chlamydia is the most common sexually transmitted disease in the United States, with 1,708,569 cases reported in $2017 .{ }^{37}$ From 2013 to 2017 , the number of reported cases of chlamydia in the United States increased by $22 \%{ }^{38}$ In neonates, the eyes can be infected after vaginal delivery by infected mothers. ${ }^{1}$ Treatment includes oral azithromycin or oral doxycycline in adults, and erythromycin in neonates.

\section{Allergic Conjunctivitis}

Most cases of allergic conjunctivitis are attributable to seasonal allergies and present with bilateral symptoms. ${ }^{1}$ Mild to severe itching and redness are the key symptoms of allergic conjunctivitis, ${ }^{18}$ which can present with a watery or mucoid discharge. ${ }^{1}$ Treatment includes supportive measures (cold compress, artificial tears), topical or oral antihistamines, and mast cell inhibitors. A short course of topical corticosteroids can be used in select cases in which corneal involvement and herpetic infection have been ruled out; both conditions could worsen with steroid use. ${ }^{1,2}$

\section{Differential Diagnosis}

To satisfy the American Academy of Ophthalmology Preferred Practice Pattern guidelines that treatment of conjunctivitis is directed at the root cause, ${ }^{1}$ physicians should manage patients by taking a systematic approach (Figure 2), considering the epidemiologic spectrum of infectious conjunctivitis, patient history, clinical exam, and - if needed-diagnostic tests.

\section{Clinical Examination}

Some initial diagnosis is necessary to exclude any potentially serious cause of acute red eye. Historical features for evaluation include pain or photophobia, which can be signs of bacterial keratitis, anterior uveitis, or acute angleclosure glaucoma. ${ }^{39}$ Associated symptoms such as upper respiratory tract infection, or known exposure to others who have presented with this, suggest a viral form of conjunctivitis. $^{39}$ Patient history of ocular trauma should be considered as a potential alternative cause of inflammation. A corneal abrasion resulting from a foreign body or exposure to the sun or ultraviolet light can present as red eye. $^{39}$ Red, painful and watery eyes due to corneal or conjunctival foreign bodies can masquerade as acute and chronic forms of conjunctivitis. Presence of a foreign body is elucidated via history, and by careful biomicroscopic exam. In those who wear contact lenses, the risk of corneal involvement and bacterial keratitis is high; therefore, these individuals should be referred to an eye care provider. ${ }^{2,39}$ Some signs and symptoms of acute infectious conjunctivitis are mimicked by dry eye disease such as hyperemia, ${ }^{32}$ grittiness and stinging. ${ }^{40}$ Adhering to the triage questions and risk factor analysis recommended by the Tear Film \& Ocular Surface Society Dry Eye Workshop II (TFOS DEWS II $)^{40}$ aids the exclusion of dry eye disease, although it may coexist with acute infectious conjunctivitis owing to the high prevalence of both conditions. Of the immune-mediated forms of conjunctivitis (eg, ocular mucous membrane pemphigoid, graft-versus-host disease, Stevens-Johnson syndrome), generally early and milder manifestations of immune-mediated conjunctivopathy may share symptomatology with acute infectious conjunctivitis because of the presence of nonspecific complaints (eg, redness, tearing, clear discharge) and conjunctival injection. ${ }^{1}$ However, these types of conjunctivitis often differ from viral conjunctivitis in their time course; they are generally protracted and more easily confused with a chronic process rather than an acute episode.

Medication history will also be informative. For example, anticoagulants are associated with subconjunctival hemorrhage, and topiramate is associated with angle-closure glaucoma. Patients requiring steroids may be at risk of more severe disease or other pathology, and referral to an eye care provider is recommended. ${ }^{2}$ The clinical examination should also include an assessment of the lymph nodes (swollen submandibular and preauricular lymph nodes). Lymphadenopathy, such as an enlarged, tender preauricular lymph node, is more common in viral versus bacterial conjunctivitis. $^{31}$

The physical eye examination should inspect for visual acuity, discharge type, corneal opacity, abnormal pupil size 


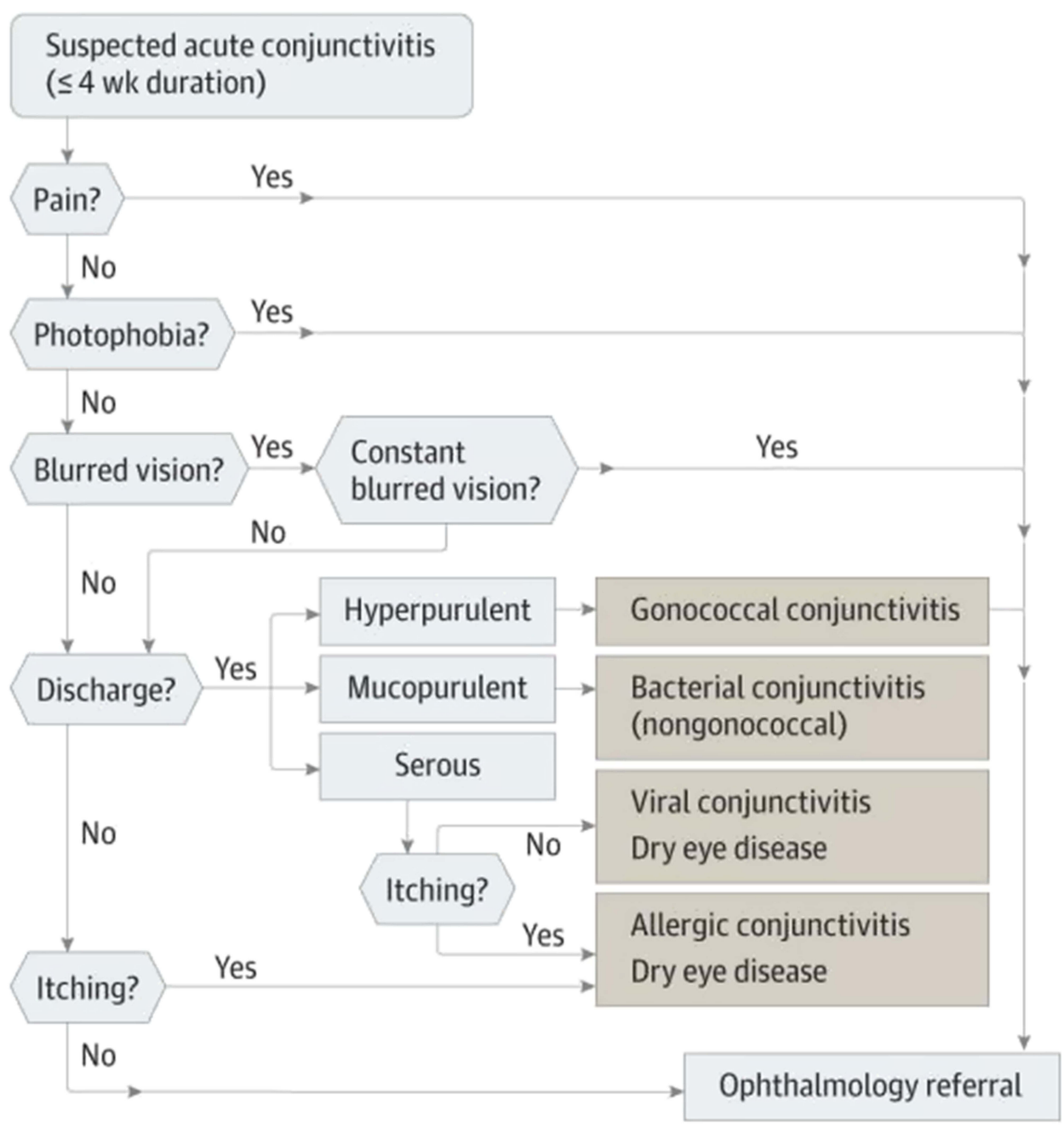

Figure 2 Differential diagnosis algorithm for suspected acute conjunctivitis. Reproduced with permission from JAMA. 2013;310(16):172I-1729. Copyright@2013 American Medical Association. All rights reserved. ${ }^{2}$

or shape, eyelid swelling, and orbit protrusion or asymmetry. ${ }^{1,2,31}$ Referral to an ophthalmologist or eye care professional should be performed immediately for cases that involve visual loss, moderate to severe pain, severe purulent discharge, or any corneal involvement. ${ }^{1,2}$ Useful information can be obtained with a simple penlight in the absence of a slit lamp, especially as it pertains to measurement of the anterior chamber depth and the ruling out of angle closure. ${ }^{2}$ Viral conjunctivitis can vary in presentation, but tearing, clear to white discharge, redness, and bilaterality are very common. Viral conjunctivitis usually starts with one eye, with the second eye to follow within a few days. ${ }^{15}$ Bacterial conjunctivitis is strongly suggested by glued eyelids, lack of itching, and lack of history of conjunctivitis. ${ }^{9}$ A diagnostic index for bacterial conjunctivitis by van Weert et al suggests that younger adult patients with conjunctivitis who present without glued eyelids at awakening are less likely to have conjunctivitis with a bacterial origin; this risk increases with age and presentation of two glued eyes. ${ }^{11}$

A slit lamp provides a more detailed appearance of the conjunctival epithelium that enables differentiation between various types of conjunctival inflammation (follicular, mainly infectious; papillary, mainly allergic; pseudomembranous, severe EKC; eosinophilic, allergic). Fluorescein staining in conjunction with slit lamp examination, highlights patterns of corneal fluorescein uptake and exposes anterior chamber inflammation. ${ }^{39} \mathrm{HSV}$ infection typically appears as branching lesions with intensely stained end bulbs, while highly branched lesions without end bulbs are typical of VZV infection. ${ }^{39}$

\section{Diagnostic Tests}

Viral diagnostic tests are not used routinely in a primary care setting, but access to these diagnostics has increased 
and may provide some guidance in obtaining a more accurate diagnosis. Polymerase chain reaction (PCR) for measurement of adenoviral DNA from tear fluid has become more common, but use of the technology is still hindered by costs of equipment and training. ${ }^{28}$ Viral cell culture with confirmatory immunofluorescence assay is time consuming and rarely performed. ${ }^{28}$

The availability of an in-office rapid test, such as AdenoPlus (Quidel, San Diego, CA, USA), to detect adenoviruses is a promising approach to obtain a timely diagnosis and reduce unnecessary use of ophthalmic antibiotics. ${ }^{6,28,41,42}$ In addition to the health benefits, use of a rapid and accurate point-of-care test for adenovirus detection could reduce societal costs associated with acute conjunctivitis. ${ }^{6}$ AdenoPlus specifically detects adenoviral serotypes through antigen-based microfiltration sampling. ${ }^{28,42}$ Observed sensitivity of the test ranges from 39.5 to $93 \% .^{28,41,42}$ Sambursky et al noted that testing conditions may cause an artificial inflation of the sensitivity, ${ }^{28}$ and Holtz et al suggested verifying negative results by real-time PCR. ${ }^{42}$ Also, clinical judgement may supersede the result of this test vis-à-vis treatment, in part because no available ophthalmic agent is indicated for the treatment of viral conjunctivitis.

Conjunctival cultures should be obtained for all diagnoses of suspected infectious neonatal conjunctivitis. ${ }^{1}$ Bacterial cultures are recommended for patients of all ages if purulent infectious conjunctivitis recurs, is severe, or becomes chronic. ${ }^{1}$ In places where culture plating is less common, ESwab (Copan Diagnostics, Murrieta, CA, USA) offers a convenient method of sample preparation for bacterial testing. ${ }^{43}$ ESwab is a liquid-based multipurpose collection and transport system that is suitable for automation, Gram stains, and traditional culture. ${ }^{43}$ Also, the ESwab system maintains testing viability of bacteria at room temperature and for $\leq 48$ hrs. $^{43}$ Suspected cases of adult and neonatal chlamydial conjunctivitis can be confirmed by diagnostic testing using an immunofluorescent antibody test and enzyme-linked immunosorbent assay. ${ }^{1}$ Testing ocular samples by PCR is not currently approved by the US Food and Drug Administration. Gram or Giemsa staining of conjunctival cytology smears is recommended for diagnosing infectious neonatal conjunctivitis or gonococcal conjunctivitis in any age group. ${ }^{1,44}$ In cases of conjunctivitis unresponsive to therapy, conjunctival biopsy in conjunction with immunofluorescent staining can be considered. ${ }^{1}$

\section{Conclusions}

Diagnosis of acute infectious conjunctivitis is complicated because of the signs and symptoms that overlap with other inflammatory conjunctival conditions; therefore, likelihood for misdiagnosis remains high. Misdiagnosis of viral conjunctivitis as bacterial conjunctivitis may result in inappropriate use of antibiotics, which in turn contributes to increased antibiotic resistance. Additionally, misdiagnosis may lead to impaired quality of life and lost productivity due to poor outcomes. Adherence to the American Academy of Ophthalmology evidence-based treatment guidelines and greater educational efforts directed at both patients and physicians could improve the management of acute infectious conjunctivitis. Prescription of antibiotics should be delayed until a bacterial etiology is confirmed, and educational pamphlets should be distributed to general and emergency care practitioners. Development of novel agents with broadspectrum antimicrobial activity may offer potential new approaches without the drawback of resistance. ${ }^{26,27,45}$

\section{Acknowledgments}

The authors thank Dr. Terry O'Brien for his helpful discussion and comments at the initial stage of this manuscript. The authors also thank Daniella Babu, PhD, of Excel Medical Affairs, who provided medical writing assistance, funded by Shire, a Takeda company.

\section{Funding}

Medical writing support was funded by Shire (a Takeda company). Shire (a Takeda company), reviewed the manuscript for medical accuracy only.

\section{Disclosure}

EY has served as a consultant for Allergan, Bausch \& Lomb, JJV, Novartis, Shire (a Takeda company), TearLab, and TissueTech, during the conduct of the study. EY has served as a consultant for Alcon, Aurea Medical, Avedro, Avellino, BioTissue, Beaver Visitec, BlephEx, Bruder, CorneaGen, Dompe, EyePoint Pharmaceuticals, iOptics, Glaukos, Guidepoint, LENSAR, Kala Pharmaceuticals, Merck, Mynosys, Ocular Science, Ocular Therapeutix, Ocusoft, Omeros, Oyster Point Pharmaceuticals, Science Based Health, Sight Sciences, Sun, Surface, TopCon, TearLab Corporation, and Zeiss, outside the submitted work. SH has served as an advisor or investigator for Allergan, Alcon, Avedro, BioTissue/TissueTech, Dompe, Eyevance, EyePoint Medical, Johnson \& Johnson, Kala, NuSight 
Medical, Ocular Therapeutix, Quidel, Shire (a Takeda company), Science Based Health, Sight Sciences, Sun, Tear Solutions, Tear Restore, and TissueTech. The authors report no other conflicts of interest in this work.

\section{References}

1. American Academy of Ophthalmology Cornea/External Disease Preferred Practice Pattern Panel. Conjunctivitis Preferred Practice Pattern ${ }^{\circledR}$. San Francisco, CA: American Academy of Ophthalmology; 2018. Available from https://www.aao.org/preferredpractice-pattern/conjunctivitis-ppp-2018. Accessed November 26, 2018.

2. Azari AA, Barney NP. Conjunctivitis: a systematic review of diagnosis and treatment. JAMA. 2013;310(16):1721-1729. doi:10.1001/ jama.2013.280318

3. Shields T, Sloane PD. A comparison of eye problems in primary care and ophthalmology practices. Fam Med. 1991;23(7):544-546.

4. Davis H, Mant D, Scott C, Lasserson D, Rose PW. Relative impact of clinical evidence and over-the-counter prescribing on topical antibiotic use for acute infective conjunctivitis. Br J Gen Pract. 2009;59 (569):897-900. doi:10.3399/bjgp09X473132

5. Kaufman HE. Adenovirus advances: new diagnostic and therapeutic options. Curr Opin Ophthalmol. 2011;22(4):290-293. doi:10.1097/ ICU.0b013e3283477cb5

6. Udeh BL, Schneider JE, Ohsfeldt RL. Cost effectiveness of a point-of-care test for adenoviral conjunctivitis. Am J Med Sci. 2008;336(3):254-264. doi:10.1097/MAJ.0b013e3181637417

7. Smith AF, Waycaster C. Estimate of the direct and indirect annual cost of bacterial conjunctivitis in the United States. $B M C$ Ophthalmol. 2009;9:13. doi:10.1186/1471-2415-9-13

8. Ohnsman CM. Exclusion of students with conjunctivitis from school: policies of state departments of health. J Pediatr Ophthalmol Strabismus. 2007;44(2):101-105. doi:10.3928/01913913-20070301-03

9. Rietveld RP, Ter Riet G, Bindels PJ, Sloos JH, van Weert HC. Predicting bacterial cause in infectious conjunctivitis: cohort study on informativeness of combinations of signs and symptoms. BMJ. 2004;329(7459):206-210. doi:10.1136/bmj.38128.631319.AE

10. Everitt HA, Little PS, Smith PW. A randomised controlled trial of management strategies for acute infective conjunctivitis in general practice. BMJ. 2006;333(7563):321. doi:10.1136/bmj.38891.551088.7C

11. van Weert HC, Tellegen E, Ter Riet G. A new diagnostic index for bacterial conjunctivitis in primary care. A re-derivation study. Eur J Gen Pract. 2014;20(3):202-208. doi:10.3109/13814788.2013.842970

12. Asbell PA, Sanfilippo CM, Pillar CM, DeCory HH, Sahm DF, Morris TW. Antibiotic resistance among ocular pathogens in the United States: five-year results from the Antibiotic Resistance Monitoring in Ocular Microorganisms (ARMOR) surveillance study. JAMA Ophthalmol. 2015;133(12):1445-1454. doi:10.1001/jamaophthalmol.2015.3888

13. Haas W, Pillar CM, Torres M, Morris TW, Sahm DF. Monitoring antibiotic resistance in ocular microorganisms: results from the Antibiotic Resistance Monitoring in Ocular micRorganisms (ARMOR) 2009 surveillance study. Am J Ophthalmol. 2011;152 (4):567-574. e3. doi:10.1016/j.ajo.2011.03.010

14. Society for Healthcare Epidemiology of America, Infectious Diseases Society of America, Pediatric Infectious Diseases Society. Policy statement on antimicrobial stewardship by the Society for Healthcare Epidemiology of America (SHEA), the Infectious Diseases Society of America (IDSA), and the Pediatric Infectious Diseases Society (PIDS). Infect Control Hosp Epidemiol. 2012;33(4):322-327. doi:10.1086/665010

15. Rietveld RP, van Weert HC, Ter Riet G, Bindels PJ. Diagnostic impact of signs and symptoms in acute infectious conjunctivitis: systematic literature search. BMJ. 2003;327(7418):789. doi:10.1136/ bmj.327.7418.789
16. Sheikh A, Hurwitz B, van Schayck CP, McLean S, Nurmatov U. Antibiotics versus placebo for acute bacterial conjunctivitis. Cochrane Database Syst Rev. 2012;9:CD001211.doi:10.1002/146518 58.CD001211.pub3

17. Rietveld RP, Ter Riet G, Bindels PJ, Schellevis FG, van Weert HC. Do general practitioners adhere to the guideline on infectious conjunctivitis? Results of the Second Dutch National Survey of General Practice. BMC Fam Pract. 2007;8:54. doi:10.1186/1471-2296-8-54

18. O'Brien TP. Allergic conjunctivitis: an update on diagnosis and management. Curr Opin Allergy Clin Immunol. 2013;13(5):543-549. doi:10.1097/ACI.0b013e328364ec3a

19. Rutala WA, Weber DJ. Selection of the ideal disinfectant. Infect Control Hosp Epidemiol. 2014;35(7):855-865. doi:10.1086/676877

20. Gordon YJ, Gordon RY, Romanowski E, Araullo-Cruz TP. Prolonged recovery of desiccated adenoviral serotypes 5,8 , and 19 from plastic and metal surfaces in vitro. Ophthalmology. 1993;100(12):1835-1839; discussion 1839-1840. doi:10.1016/S0161-6420(93)31389-8

21. Pihos AM. Epidemic keratoconjunctivitis: a review of current concepts in management. J Optom. 2013;6(2):69-74. doi:10.1016/j. optom.2012.08.003

22. Jhanji V, Chan TC, Li EY, Agarwal K, Vajpayee RB. Adenoviral keratoconjunctivitis. Surv Ophthalmol. 2015;60(5):435-443. doi:10.1016/j.survophthal.2015.04.001

23. Rajaiya J, Chodosh J. New paradigms in infectious eye disease: adenoviral keratoconjunctivitis. Arch Soc Esp Oftalmol. 2006;81(9):493-498.

24. Meyer-Rusenberg B, Loderstadt U, Richard G, Kaulfers PM, Gesser C. Epidemic keratoconjunctivitis: the current situation and recommendations for prevention and treatment. Dtsch Arztebl Int. 2011;108(27):475-480. doi:10.3238/arztebl.2011.0475

25. Romanowski EG, Roba LA, Wiley L, Araullo-Cruz T, Gordon YJ. The effects of corticosteroids of adenoviral replication. Arch Ophthalmol. 1996;114(5):581-585. doi:10.1001/archopht.1996.01100130573014

26. Pepose JS, Ahuja A, Liu W, Narvekar A, Haque R. Randomized, controlled, phase 2 trial of povidone-iodine/dexamethasone ophthalmic suspension for treatment of adenoviral conjunctivitis. Am J Ophthalmol. 2018;194(10):7-15. doi:10.1016/j.ajo.2018.05.012

27. Teuchner B, Nagl M, Schidlbauer A, et al. Tolerability and efficacy of $\mathrm{N}$-chlorotaurine in epidemic keratoconjunctivitis-a double-blind, randomized, phase-2 clinical trial. J Ocul Pharmacol Ther. 2005;21 (2):157-165. doi: 10.1089/jop.2005.21.157

28. Sambursky R, Trattler W, Tauber S, et al. Sensitivity and specificity of the AdenoPlus test for diagnosing adenoviral conjunctivitis. JAMA Ophthalmol. 2013;131(1):17-22. doi:10.1001/2013.jamaophthalmol.513

29. Baneke AJ, Lim KS, Stanford M. The pathogenesis of raised intraocular pressure in uveitis. Curr Eye Res. 2016;41(2):137-149. doi: $10.3109 / 02713683.2015 .1017650$

30. Li JY. Herpes zoster ophthalmicus: acute keratitis. Curr Opin Ophthalmol. 2018;29(4):328-333. doi:10.1097/ICU.0000000000000491

31. O'Brien TP, Jeng BH, McDonald M, Raizman MB. Acute conjunctivitis: truth and misconceptions. Curr Med Res Opin. 2009;25 (8):1953-1961. doi:10.1185/03007990903038269

32. Yamaguchi T. Inflammatory response in dry eye. Invest Ophthalmol Vis Sci. 2018;59(14):DES192-DES199. doi:10.1167/iovs.17-23651

33. Blank S, Daskalakis DC. Neisseria gonorrhoeae - rising infection rates, dwindling treatment options. $N$ Engl $J$ Med. 2018;379 (19):1795-1797. doi:10.1056/NEJMp1812269

34. Centers for Disease Control and Prevention. Sexually transmitted disease surveillance 2017. Gonorrhea. Available from: https://www.cdc. gov/std/stats17/Gonorrhea.htm\#ref3. Accessed February 4, 2019.

35. Centers for Disease Control and Prevention. New CDC analysis shows steep and sustained increases in STDs in recent years. August 2018 Press Release. Available from: https://www.cdc.gov/media/releases/2018/ p0828-increases-in-stds.html. Accessed February 21, 2019.

36. Workowski KA, Bolan GA;Centers for Disease Control and Prevention. Sexually transmitted diseases treatment guidelines, 2015. MMWR Recomm Rep. 2015;64(RR-03):1-137. 
37. Centers for Disease Control and Prevention. Sexually transmitted disease surveillance 2017. Chlamydia. Available from: https://www. cdc.gov/std/stats17/chlamydia.htm. Accessed February 21, 2019.

38. Centers for Disease Control and Prevention. Sexually transmitted disease surveillance 2017. Table 1. Sexually transmitted diseases reported cases and rates of reported cases per 100,000 Population, United States, 1941-2017. Available from: https://www.cdc.gov/std/ stats 17/tables/1.htm. Accessed February 21, 2019.

39. Gilani CJ, Yang A, Yonkers M, Boysen-Osborn M. Differentiating urgent and emergent causes of acute red eye for the emergency physician. West J Emerg Med. 2017;18(3):509-517. doi:10.5811/ westjem.2016.12.31798

40. Craig JP, Nichols KK, Akpek EK, et al. TFOS DEWS II definition and classification report. Ocul Surf. 2017;15(3):276-283. doi:10. 1016/j.jtos.2017.05.008

41. Kam KY, Ong HS, Bunce C, Ogunbowale L, Verma S. Sensitivity and specificity of the AdenoPlus point-of-care system in detecting adenovirus in conjunctivitis patients at an ophthalmic emergency department: a diagnostic accuracy study. Br J Ophthalmol. 2015;99 (9):1186-1189. doi:10.1136/bjophthalmol-2014-306508
42. Holtz KK, Townsend KR, Furst JW, et al. An assessment of the AdenoPlus point-of-care test for diagnosing adenoviral conjunctivitis and its effect on antibiotic stewardship. Mayo Clin Proc Innov Qual Outcomes. 2017;1(2):170-175. doi:10.1016/j.mayocpiqo. 2017.06.001

43. ESwab ${ }^{\mathrm{TM}}$. Sample collection, transport \& processing. Murrieta, CA: COPAN Diagnostics Inc. Available from: http://www.copanusa. com/sample-collection-transport-processing/. Accessed December 14, 2018.

44. Mallika P, Asok T, Faisal H, Aziz S, Tan A, Intan G. Neonatal conjunctivitis - a review. Malays Fam Physician. 2008;3(2):77-81.

45. Zirgan (ganciclovir ophthalmic gel $0.15 \%$ ) prescribing information. Bausch and Lomb. Available from: https://www.bausch.com/Portals/ 69/-/m/BL/United\%20States/USFiles/Package\%20Inserts/Pharma/zir ganpackageinsert.pdf. Accessed December 18, 2018.
Clinical Ophthalmology

\section{Publish your work in this journal}

Clinical Ophthalmology is an international, peer-reviewed journal covering all subspecialties within ophthalmology. Key topics include: Optometry; Visual science; Pharmacology and drug therapy in eye diseases; Basic Sciences; Primary and Secondary eye care; Patient Safety and Quality of Care Improvements. This journal is indexed on PubMed

Submit your manuscript here: https://www.dovepress.com/clinical-ophthalmology-journal
Dovepress

Central and CAS, and is the official journal of The Society of Clinical Ophthalmology (SCO). The manuscript management system is completely online and includes a very quick and fair peer-review system, which is all easy to use. Visit http://www.dovepress.com/ testimonials.php to read real quotes from published authors. 